New-Wave

\title{
Knitting
}

\section{Resources for a} Core Collection

\section{Kathleen Collins, Guest Columnist}

\author{
Correspondence concerning this \\ column should be addressed to \\ Neal Wyatt, The Alert Collector, c/o \\ RUSA, 50 E. Huron, Chicago, IL 60611; \\ e-mail:alertcollector@comcast.net. \\ Wyatt is a collection development \\ and readers' advisory librarian from \\ Virginia. She wrote The Readers' \\ Advisory Guide to Nonfiction \\ (ALA Editions, 2007), is the editor of \\ Library Journal's "Reader's Shelf" \\ column, author of Booksmack!'s "RA \\ Crossroads" column, and compiles LJ's \\ weekly "Wyatt's World Lists." \\ Kathleen Collins is the Coordinator \\ of Reference Services at the Odegaard \\ Undergraduate Library at the \\ University of Washington in Seattle.
}

As the crafting trend continues apace, knitting remains very popular as the seemingly endless number of titles published on the subject, in print and online, can attest. How do we know which books and resources will best serve our patrons, and where do we turn for guidance and hands-on (as it were) reviews? Kathleen Collins, the coordinator of Reference Services for the Odegaard Undergraduate Library at the University of Washington (UW) and a sociology subject librarian and children's and young adult literature librarian for the UW Libraries, offers thirty-eight resources that can create and support a knitting core collection. Collins taught herself to knit fifteen years ago from library books. Her guides were Maggie Righetti's Knitting in Plain English, Barbara Walker's Learn-to-Knit Afghan Book, and a small pamphlet she's long since lost. She currently has a shelf full of knitting books, three hampers' worth of yarn stash, and six projects in progress on the needles.-Editor

$\mathrm{H}$ and-knitting has a long social history; the earliest known knitted garments are cotton sock fragments found in Egypt and dated to about two thousand years ago. With the invention of the knitting machine and the industrialization of cloth and garment manufacture, knitting at home became less of a necessity and more of a craft, and as such it has gone in and out of vogue many times in the two centuries since the Industrial Revolution. During the last decade it has enjoyed a particularly vigorous revival, and women (and some men) both young and old can frequently be seen knitting in public_-on buses and in coffee shops, in book groups and at ALA conferences.

Periodic surveys conducted by the Craft Yarn Council of America (www.craftyarncouncil.com) indicate that in the last ten years the number of new knitters has grown by large numbers. An increasing number of those new to knitting, while continuing to rely on printed materials and drawing inspiration from the knitting giants of previous generations (Elizabeth Zimmermann, Barbara Walker, Kaffe Fassett), also turn to the Internet for knitting inspiration. Online magazines, knitting blogs, and social networking groups have become the cradle for a new generation of knitting designers.

This column is, first and foremost, an attempt to reflect the wide and wired world of contemporary knitting and to recommend to public libraries a selection of knitting resources that highlight the major knitting authors, techniques, and trends from the past decade. As such, the emphasis of the core collection presented here is on breadth rather than depth-major trends like felting are represented by a single book-and on profiles rather than patterns. After all, the 
new-wave knitter well knows that he or she can supplement the printed project books available in the library with additional resources from the web.

\section{WEBSITES}

\section{Knitty.com}

Amy Singer founded this influential web-only magazine "with a sense of humor and absolutely no doily patterns" in 2002. Each quarterly issue contains projects by up-andcoming designers (difficulty ratings range playfully from mellow, to tangy, to piquant, to extra spicy), feature articles, and a "Cool Stuff" column that reviews books, yarns, tools, and accessories.

\section{Ravelry.com}

The Facebook of the fiber crowd launched in 2007 and now has 1 million members. Ravelry provides a place for knitters to keep track of their yarn stashes, needles, projects, and patterns. In the patterns section users can see how a particular design looks when made by real knitters using different yarns. Members can follow favorite designers and interact with other knitters on forums like "RaveLibrarians" and "Sheepless in Seattle." The site requires a log-in, but membership is free.

Knitter's Review (http://knittersreview.com)

Clara Parkes, the author of The Knitter's Book of Yarn, writes this high-quality site of frank and in-depth yarn, book, and tool reviews, how-to tips, and active user forums. It is updated weekly, and readers can sign up to receive the free weekly newsletter via e-mail or RSS feed. Archives stretch back to 2000, making this the grandmother of online knitting sites.

\section{MAGAZINES}

Cast On. Zanesville, Ohio: Knitting Guild Association, 1984-. 5/year. (ISSN: 1557-573X). www.tkga.com.

The official publication of The Knitting Guild Association (formerly The Knitting Guild of America) contains the usual projects, but the teaching articles (about six in each issue) make it really stand out from other knitting magazines. The emphasis on clearly presented instructions makes it particularly useful for those learning to knit.

Interweave Knits. Loveland, Colo.: Interweave, 1996- Quarterly. (ISSN: 1088-3622). www.interweaveknits.com.

This magazine stands out from its competitors because of its particularly exciting projects-twenty or more in each issue, plus three to five feature articles profiling designers and discussing knitting trends and techniques.

\section{REFERENCE WORKS}

Epstein, Nicky. Knitting on the Edge: Ribs, Ruffles, Lace, Fringes, Flora, Points and Picots: The Essential Collection of 350
Decorative Borders. New York: Sixth \& Spring, 2004 (ISBN: 978-1-93154-340-8).

The perfect complement to more traditional stitch dictionaries, Epstein's thorough exploration of edgings invites the knitter to get creative in embellishing projects. Amazing photography and simple instructions enhance the usability of this excellent and inviting reference book. Epstein's followups include Knitting Over the Edge (2005) and Knitting Beyond the Edge (2006).

Harmony Guides series. Loveland, Colo.: Interweave, 2007-9.

Knight, Erika. Knit \& Purl: 250 Stitches to Knit. (ISBN: 9781-5966-8056-2); Knight, Erika. Cables and Arans: 250 Stitches to Knit. (ISBN: 978-1-5966-8058-6); Knight, Erika. Lace and Eyelets: 250 Stitches to Knit. (ISBN: 978-1-5966-80579); Haxell, Kate. Knit Edgings and Trims: 150 Stitches. (ISBN: 978-1-5966-8173-6); Brant, Sharon. Colorwork Stitches: 250 Designs to Knit. Loveland, Colo.: Interweave, 2009. (ISBN: 978-1-5966-8147-7).

This handsome set supplements the classic volumes in Barbara Walker's Treasury of Knitting Stitches. Each page shows one or two stitch patterns, accompanied by full-color photographs illustrating the completed swatches. General tips sprinkled throughout the volumes are marked by a yarn ball icon. Each volume has a brief index to the stitches-something that many stitch dictionaries neglect. Essential for all libraries that do not already own the older Harmony Guides or the competing five-volume Vogue Stitchionaries.

Vogue Knitting: The Ultimate Knitting Book. New York: Sixth and Spring, 2002 (ISBN: 978-1-9315-4316-3).

This fat reference book is a comprehensive guide to knitting, covering basic and advanced techniques, and needles and other supplies. It includes a dictionary of common stitches, fixes for common problems, and much more. Beginning knitters may be intimidated by its size and scope, but those who have mastered the basics will value Vogue Knitting's encyclopedic coverage.

\section{KNITTING DESIGN AND TECHNIQUE}

Budd, Ann. The Knitter's Handy Book of Patterns: Basic Designs in Multiple Sizes and Gauges. Loveland, Colo.: Interweave, 2002 (ISBN: 978-1-9314-9904-0).

This ingenious book allows the knitter to create basic garments (mittens, gloves, hats, scarves, tams, sweaters, vests, and socks) in any size, with any yarn and needle, by using an easy-to-follow matrix that gives directions for child to adult sizes in multiple gauges. Budd, the former managing editor of Interweave Knits, is also the author of The Knitter's Handy Book of Sweater Patterns (2004).

Davis, Jane. Felting: The Complete Guide. Cincinnati, Ohio: Krause, 2009 (ISBN: 978-0-8968-9590-4).

Felting is the latest knitting craze, and this guide is an 


\section{ACCIDENTAL TECHNOLOGIST}

excellent and informative introduction to the full range of techniques, materials, and tools used in the craft. The book contains thirty-six projects from beginning to advanced, and includes step-by-step photos to guide the novice. More advanced felters will also appreciate Nicky Epstein's Knitting Never Felt Better (2007).

Melville, Sally. The Knitting Experience. Sioux Falls, S. Dak.: XRX, 2002-5.

Book 1: The Knit Stitch, Inspiration and Instruction. (ISBN: 978-1-8937-6213-8): Book 2: The Purl Stitch, Becoming Intuitive. (ISBN: 978-1-8937-6214-5): Book 3: Color, The Power and the Glory. (ISBN: 978-1-9330-6402-4).

Adventurous beginners and veterans alike will devour this three-volume primer that encourages experimentation while introducing the foundations of knitting. Melville covers the basics, supplies different options, and then combines the skills in the projects she presents. With excellent instructions and detailed patterns, this book is especially helpful for knitters who are teaching themselves without benefit of a live knitting instructor.

Parkes, Clara. The Knitter's Book of Yarn: The Ultimate Guide to Choosing, Using, and Enjoying Yarn. New York: Potter Craft, 2007 (ISBN: 978-0-3073-5216-3).

Anyone who has walked into a yarn store will be boggled by the choices presented. Parkes, the editor of the online Knitter's Review, tackles the tough task of demystifying those choices, covering the qualities of various fibers along with the different ways to turn them into yarn. The patterns apply this information, demonstrating the best uses for each fiber employed.

Radcliffe, Margaret. The Essential Guide to Color Knitting Techniques. North Adams, Mass.: Storey, 2008 (ISBN: 9781-6034-2040-2).

A must-have resource for all projects that involve more than a single color of yarn, this guide walks the knitter through the gamut of multicolor knitting techniques with step-by-step photo illustrations. The techniques covered range from simple stripes through the complications of intarsia and Fair Isle all the way to rarer techniques like shadow and mosaic. Radcliffe includes tips on common problems like handling multiple strands of yarn and weaving ends back into the main color pattern.

Radcliffe, Margaret. The Knitting Answer Book. North Adams, Mass.: Storey, 2005 (ISBN: 978-1-5801-7599-9).

This tiny little volume functions as the book equivalent to a knitting FAQ. Radcliffe tackles questions that straight how-to guides skip over and addresses common dilemmas encountered by new and experienced knitters alike.

Righetti, Maggie. Knitting in Plain English, updated edition.
New York: St. Martin's, 2007 (ISBN: 978-0-3123-5353-7).

Righetti is an experienced knitting teacher whose guide for the beginning-to-intermediate knitter is sprinkled with salty comments about bad knitting patterns, practical tips for varying basic knitting stitches, and advice on correcting common mistakes. Refreshingly frank and plain-spoken, Righetti manages to demystify knitting while retaining a healthy reverence for the craft. Originally published in 1986 and now updated with new illustrations and details.

Vogel, Lynne. The Twisted Sisters Knit Sweaters: A Knit-to-Fit Workshop. Loveland, Colo.: Interweave, 2007 (ISBN: 978-19314-9969-9).

This thorough introduction to the basic elements of sweater design and construction guides knitters step-by-step through the process of adapting sweater patterns to suit their personal preferences and creative urges. Vogel covers bodice fitting, using different yarns, and changing proportions, necklines, edgings, sleeves, and colors and stitches. For another book on sweater design, consider Margaret Fisher's Seven Things That Can "Make or Break" a Sweater (2008).

Watterson, Lynne. The Very Easy Guide to Cable Knitting. New York: St. Martin's Griffin, 2010 (ISBN: 978-0-3126-0899-6).

The truth is in the title-this is indeed a very easy and inviting introduction to the technique of cabling, including a series of step-by-step lessons on different cable techniques. The photographs of cable swatches knit up in different types of yarn is an especially helpful touch for illustrating how yarn choice can impact a cable's look and texture. For more advanced cablers, consider Melissa Leapman's Cables Untangled (2006).

Wiseman, Nancie. The Knitter's Book of Finishing Techniques. Woodinville, Wash.: Martingale, 2002 (ISBN: 978-1-56477452-1).

Careful finishing techniques can make the difference in producing a polished end piece, and this book goes through them all with matter-of-fact directions and clear illustrations. This reference covers binding off, weaving in yarn ends, various seams, grafting stitches, hemming knitted items, i-cord binding, crocheted edges, and all the other details the knitter must tend to after a knitted piece leaves the needles.

\section{FOCUS ON KNITTING FOR BABIES AND KIDS}

Anderson, Susan B. Itty-Bitty Nursery. New York: Artisan, 2007 (ISBN: 978-1-5796-5334-7).

Anderson strikes a perfect balance between the practical (sweaters, caps and blankets, a tote bag for mom) and whimsical (a set of knitted peas and carrots, a cupcake tea set, an adorable bunch of mice to adorn a nursery mobile) in her inaugural collection of baby patterns for intermediate knitters.

Bliss, Debbie. Baby Knits for Beginners. North Pomfret, Vt.: 
Trafalgar Square, 2003 (ISBN: 978-1-5707-6248-2).

Bliss, the reigning queen of baby knits, presents realistic projects to start off beginners, covering some of the basics of knitting stitches and garment construction before presenting a few simple classic patterns: a garter stitch scarf, a pair of seed stitch shoes, a basic cardigan and v-neck. Once knitters complete some of these basic projects, they'll be ready to move on to the slightly more complicated items in Bliss's follow-up books Simply Baby (2006) and Essential Baby (2007).

Guy, Lucinda, and François Hall. Handknits for Kids: 25 Original Designs for Girls and Boys. North Pomfret, Vt.: Trafalgar Square, 2005 (ISBN: 978-1-5707-6310-6).

Guy presents fun and funky patterns for girls and boys ages two to five, for garments, accessories, blankets, and toys. The photographs of the knitted pieces that make up the final project (for instance, all of the individual pieces that, when assembled, form the "Handsome Hound") are an especially useful visualization. Hall's charming illustrations add a whimsical touch. Guy's other books of kid knits include And So To Bed (2006) and Knitting Motifs for Babies and Kids (2010).

\section{FOCUS ON KNITTING SOCKS}

Bordhi, Cat. Socks Soar on Two Circular Needles. Friday Harbor, Wash.: Passing Paws, 2001 (ISBN: 978-0-9708-8695-8).

This slender book packs a lot of information into its fortyfour pages. Knitting socks on two circular needles increases the speed with which a sock can be completed. Bordhi explains the technique in simple language, describes how to convert traditional sock patterns for use with two circulars, and supplies eleven original patterns using the two-circulars technique. Antje Gillingham's Knitting More Circles Around Socks: Two at a Time, Toe Up or Cuff Down (2009) also will appeal to knitters interested in novel sock-knitting techniques.

Budd, Ann. Getting Started Knitting Socks. Loveland, Colo.: Interweave, 2007 (ISBN: 978-1-5966-8029-6).

This is the perfect book for the new sock-knitter. An opening section covers basic techniques and discusses options- the long-tail cast-on versus the Old Norwegian, knitting on four double-points versus using five. Budd presents five basic patterns for five different sock gauges and then adds some simple variations that add color and texture. The author doesn't dazzle here with advanced designs, and her solid introduction to sockknitting is all the stronger for that. Knitters who master this foundation are ready to move on to Budd's collection Favorite Socks: 25 Timeless Designs from Interweave (2006).

Rowley, Elaine, and Alexis Xenakis. Think Outside the Sox. Sioux Falls, S. Dak.: XRX, 2010 (ISBN: 978-1-9330-6418-5).

Featuring more than sixty of the winning designs from Knitter's Magazine's international sock-knitting contest, this collection of patterns includes top-up and top-down designs that employ advanced techniques like colorwork, cables, lace, and Latvian braids. It is everything that Budd's book Getting Started Knitting Socks isn't, and as such is a perfect complement.

\section{PROFILES AND PROJECTS}

The Style series, Pam Allen and Ann Budd, series editors. Loveland, Colo.: Interweave, 2004-9

Scarf Style, 2004 (ISBN: 978-1-9314-9954-5); Wrap Style, 2005 (ISBN: 978-1-9314-9991-0); Lace Style, 2007 (ISBN: 978-1-5966-8028-9); Folk Style, 2007 (ISBN: 978-1-59668020-3); Bag Style, 2008 (ISBN: 978-1-5966-8043-2); Color Style, 2008 (ISBN: 978-1-5966-8062-3); Simple Style, 2009 (ISBN: 978-1-5966-8090-6).

A lovely and popular series of themed project books featuring the work of well-known designers (Norah Gaughan, Nancy Bush, Leigh Radford) and presenting refreshingly different styles in a range of knitting techniques (cabling, entrelac, short rows, lace, color work). Especially notable in this series is the "Design Notebook" section, which presents basic ideas and design techniques that encourage the knitter to go beyond the patterns presented in each collection.

Budd, Ann. Knitting Green: Conversations and Planet-Friendly Projects. Loveland, Colo.: Interweave, 2010 (ISBN: 978-15966-8166-8).

Budd assembled twenty-two simple patterns on a "green" theme, most using yarns that self-identify as "eco-friendly." However, the real meat of the book is in the essays, which explore issues surrounding green knitting. Clara Parkes writes about eco-friendly fibers, Pam Allen meditates on the meaning of the word "organic," and yarn store owner Lisa Myers writes about "green retailing." Knitters will find that this book is thought provoking yet offers practical solutions for knitting with the environment in mind.

Christiansen, Betty. Knitting for Peace. New York: Stewart, Tabori \& Chang, 2006 (ISBN: 978-1-5847-9533-9).

Following in a long tradition of charity knitting, this book profiles twenty-four contemporary groups dedicated to helping others through knitting and presents thirteen simple projects with which the knitter can contribute. From the Mother Bear Project, providing knit bears to children with HIV/AIDS in emerging nations, to Afghans for Afghans, sending handmade blankets and other warm items to people in Afghanistan, knitters with a social conscience will surely find a cause that will inspire them to pick up their needles.

Del Vecchio, Michael. Knitting with Balls: A Hands-on Guide to Knitting for the Modern Man. New York: DK, 2006 (ISBN: 978-0-7566-2289-3).

Del Vecchio, the cofounder of the now-defunct online magazine Menknit.net, tackles the topic of men who knit with self-deprecating humor while presenting patterns for 


\section{ACCIDENTAL TECHNOLOGIST}

hats, scarves, socks, a laptop cover, and a beer cozy that will appeal to male knitters. The book also provides advice on how to resize and reshape patterns meant for women to suit the male knitter, and the back-of-the-book list of knitting resources includes several that are male-friendly.

Durham, Teva. Loop-D-Loop. New York: STC Craft, 2005 (ISBN: 978-1-5847-9414-1).

Durham's imaginative takes on familiar knitting concepts are underpinned by her appreciation of geometry. Patterns are divided into the three general sections: cycles (using tubes, spirals, or round shapes), planes (using textures and diagonals), and waves (blending color and composition). In each section an essay explains the concept and then the patterns apply it. Durham's novel blend of math and imagination makes this book a stand-out. Lynne Barr's Knitting New Scarves (2007) will also appeal to knitters inspired by Loop-D-Loop.

Falick, Melanie. America Knits. New York: Artisan, 2005 (ISBN: 978-1-5796-5287-6). (First published in hardcover as Knitting in America: Patterns, Profiles, and Stories of America's Leading Artisans. Artisan, 1996.)

Falick selects thirty-eight people who support themselves with fiber-by knitting, spinning, dying, designing patterns, or breeding sheep - and presents their stories side-by-side with the patterns they designed especially for the book and accompanied by lovely photographs by Chris Hartlove. The thirty-eight patterns are mostly for intermediate knitters and amply demonstrate the flexibility of knitting as craft, but the real value is in Falick's respectful and deeply personal portraits of these people and their work.

Gardiner, Kay, and Ann Shayne. Mason-Dixon Knitting: The Curious Knitters' Guide. New York: Potter Craft, 2006 (ISBN: 978-0-3075-8645-2).

Gardiner and Shayne are the voices behind Mason-Dixon Knitting (masondixonknitting.com), a compulsively readable epistolary blog. The book captures the "just between friends" tone of the blog perfectly, offering practical advice, tart observations, and thirty patterns for everything from dishcloths to sophisticated blankets. Whether extolling the virtues of humble kitchen cotton or "yarn scribbling" to create the Decayed Tutu Scarf, the authors encourage knitting with a spirit of fun and experimentation. The sequel is Mason-Dixon Knitting: Outside the Lines (2008).

Moreno, Jillian and Amy R. Singer. Big Girl Knits. New York: Potter Craft, 2006 (ISBN: 978-0-3075-8637-7).

Recent reports indicate that the average American woman now wears a size fourteen. Skillfully and sensitively, Moreno and Singer address this reality in a book meant for plus-size women. The first section covers broader issues of designing and knitting for plus-sized bodies and the typical problem areas, which they bluntly describe as "the three Bs—boobs, butt, and belly." The projects themselves are designed to flatter larger bodies. The authors followed up with More Big Girl Knits (2008).

Singer, Amy R. No Sheep for You. Loveland, Colo.: Interweave, 2007 (ISBN: 978-1-5966-8012-8).

Like many people, Singer, the founder of Knitty.com, is allergic to wool. She focuses on exploring wool alternatives in this chatty and informative fiber-guide-cum-pattern-book. The first section discusses the pros and cons of cotton, linen, hemp, silk, bamboo, soy, and other non-wool fibers in very practical terms. More helpful fiber hints are tucked into the pattern section, which showcases many garments normally knit in wool-intricate colorwork sweaters, shawls, and even thrummed mittens.

Stoller, Debbie. Stitch 'n Bitch: The Knitter's Handbook. New York: Workman, 2003 (ISBN: 978-0-7611-2818-2).

If there is one book that captures the knitting zeitgeist of the past decade, this is it. Fortunately, Stitch ' $n$ Bitch is not just another "hip" knitting book. Stoller is editor-in-chief of BUST magazine, and she has produced a how-to-knit manual, feminist knitting manifesto, pattern book, and guide to the social knitting community all rolled into one. Patterns, largely designed by nonprofessional designers, are whimsically titled and list the skills needed to complete them.

Turjoman, Julie. Brave New Knits: 26 Projects and Personalities from the Knitting Blogosphere. Emmaus, Pa.: Rodale, 2010 (ISBN: 978-1-6052-9590-9).

With a forward by Jessica Marshall Forbes, the cofounder of Ravelry.com, this is not the typical pattern book. Although the projects themselves are interesting (Melissa Wehrle's Origami Shrug is especially fine), the book really shines in its profiles of the designers, all of whom got their start in cyberspace. In introducing bloggers like Kathy Veeza (aka "Grumperina") and Wendy Bernard of "Knit and Tonic," Brave New Knits provides the reader with a manageable entry point into the ever-widening knitting blogosphere.

\section{WRITING ABOUT KNITTING}

MacDonald, Anne L. No Idle Hands: The Social History of American Knitting. New York: Ballantine, 1988 (ISBN: 9780-3453-6253-7).

Scholarly yet accessible, MacDonald's landmark work was the first detailed examination of the place of knitting in American life. Based on diaries, letters, and personal accounts, the book documents the story of hand-knitting in America from colonial times onward, placing it in the context of surrounding history (wars, the westward expansion, the suffrage movement), touching on fads and trends, and slipping in bits of knitting trivia along the way. 
Pearl-McPhee, Stephanie. Yarn Harlot: The Secret Life of a Knitter. Kansas City, Mo.: Andrews McMeel, 2005 (ISBN: 978-0-7407-5037-3).

The first of a series of greatest hits compilations based on the popular knitting blog Yarn Harlot (yarnharlot.ca), this collection of thirty-seven brief essays provides chuckles (as in a series of comic pieces chronicling her obsessive yarn collection) and tears (a poignant reflection on her grandmother, a professional knitter and a "hard woman to love"). Pearl-McPhee's writings will strike a chord of recognition in every addicted knitter.
Wills, Kerry. A Close-Knit Circle: American Knitters Today. American Subcultures series. Westport, Conn.: Praeger, 2007 (ISBN: 978-0-2759-9246-0).

Journalist and knitter Wills covers the subcultures of contemporary American knitting in this engaging academic treatment. Covering everything from the influence of Elizabeth Zimmermann to the wildfire appeal of the famous "Clapotis" (Knitty.com's most popular pattern ever) and touching along the way on knitting books, blogs, clubs, museum exhibits, and even Debbie Macomber's knitting novels, this is one book that will appeal to public and academic libraries alike. 